Article

\title{
Protective Effects of Quercetin on Oxidative Stress-Induced Tubular Epithelial Damage in the Experimental Rat Hyperoxaluria Model
}

\author{
Ahmet Guzel ${ }^{1, * \mathbb{D}}$, Sedat Yunusoglu ${ }^{2}$, Mustafa Calapoglu ${ }^{3}$, Ibrahim Aydın Candan ${ }^{4}$, Ibrahim Onaran ${ }^{5}$, \\ Meral Oncu ${ }^{6}$, Osman Ergun ${ }^{7}$ and Taylan Oksay ${ }^{7}$ \\ 1 Department of Urology, Aydın State Hospital, Aydın 09100, Turkey \\ 2 Department of Urology, Afyonkarahisar State Hospital, Afyonkarahisar 03100, Turkey; \\ sedat.yunusoglu@saglik.gov.tr \\ 3 Department of Biochemistry, Faculty of Arts and Science, Suleyman Demirel University, \\ Isparta 32100, Turkey; calapoglu@hotmail.com \\ 4 Department of Histology and Embryology, Faculty of Medicine, Alanya Alaaddin Keykubat University, \\ Antalya 07100, Turkey; ibrahim.candan@alanya.edu.tr \\ 5 Department of Medical Biology, Faculty of Medicine, Suleyman Demirel University, Isparta 32100, Turkey; \\ ibrahimonaran@sdu.edu.tr \\ 6 Department of Histology and Embryology, Faculty of Medicine, Suleyman Demirel University, \\ Isparta 32100, Turkey; meraloncu@sdu.edu.tr \\ 7 Department of Urology, Faculty of Medicine, Suleyman Demirel University, Isparta 32100, Turkey; \\ osmanergun@sdu.edu.tr (O.E.); taylanoksay@sdu.edu.tr (T.O.) \\ check for \\ updates \\ * Correspondence: ahmet.guzel6@saglik.gov.tr; Tel.: +90-505-303-94-14
}

Citation: Guzel, A.; Yunusoglu, S.; Calapoglu, M.; Candan, I.A.; Onaran,

I.; Oncu, M.; Ergun, O.; Oksay, T. Protective Effects of Quercetin on Oxidative Stress-Induced Tubular Epithelial Damage in the Experimental Rat Hyperoxaluria Model. Medicina 2021, 57, 566. https://doi.org/10.3390/medicina 57060566

Academic Editor: Giuseppe Lucarelli

Received: 22 April 2021

Accepted: 25 May 2021

Published: 3 June 2021

Publisher's Note: MDPI stays neutral with regard to jurisdictional claims in published maps and institutional affiliations.

Copyright: (c) 2021 by the authors. Licensee MDPI, Basel, Switzerland. This article is an open access article distributed under the terms and conditions of the Creative Commons Attribution (CC BY) license (https:/ / creativecommons.org/licenses/by/ $4.0 /)$.
Abstract: Background and Objectives: The most common kidney stones are calcium stones and calcium oxalate $(\mathrm{CaOx})$ stones are the most common type of calcium stones. Hyperoxaluria is an essential risk factor for the formation of these stones. Quercetin is a polyphenol with antioxidant, anti-inflammatory, and many other physiological effects. The aim of this study was to investigate the protective effect of quercetin in hyperoxaluria-induced nephrolithiasis. Materials and Methods: Male Wistar-Albino rats weighing 250-300 g ( $n=24)$ were randomized into three groups: Control $(n=8)$, ethylene glycol (EG) $(n=8)$, and EG + quercetin $(n=8)$. One percent EG-water solution was given to all rats except for the control group as drinking water for five weeks. Quercetin-water solution was given to the $\mathrm{EG}+$ quercetin group by oral gavage at a dose of $10 \mathrm{mg} / \mathrm{kg} /$ day. Malondialdehyde (MDA), catalase (CAT), urea, calcium, and oxalate levels were analyzed in blood and urine samples. Histopathological assessments and immunohistochemical analyses for oxidative stress and inflammation indicators p38 mitogen-activated protein kinase (p38-MAPK) and nuclear factor kappa B (NF-kB) were performed on renal tissues. Results: The MDA levels were significantly lower in the quercetin-treated group than in the EG-treated group $(p=0.001)$. Although CAT levels were higher in the quercetin-treated group than the EG-administered group, they were not significantly different between these groups. The expression of p38 MAPK was significantly less in the quercetin-treated group than the EG group $(p<0.004)$. There was no statistically significant difference between the quercetin and EG groups in terms of NF-kB expression. Conclusions: We conclude that hyperoxaluria activated the signaling pathways, which facilitate the oxidative processes leading to oxalate stone formation in the kidneys. Our findings indicated that quercetin reduced damage due to hyperoxaluria. These results imply that quercetin can be considered a therapeutic agent for decreasing oxalate stone formation, especially in patients with recurrent stones due to hyperoxaluria.

Keywords: calcium oxalate; hyperoxaluria; oxidative stress; quercetin

\section{Introduction}

Urinary stone formation involves several factors, including the concentration of ions causing stone formation, urine $\mathrm{pH}$, urinary flow rates, and urinary tract anatomy [1]. Ap- 
proximately $75 \%$ of the renal stones are calcium stones, and calcium oxalate $(\mathrm{CaOx})$ stones are the most commonly encountered calcium stones [2,3]. It is known that hyperoxaluria is an essential risk factor for the formation of these stones. The resultant increase in urinary oxalate concentration induces stone formation via calcium and oxalate ions to form $\mathrm{CaOx}$ crystals at physiological $\mathrm{pH}$. It was demonstrated that the excess oxalate concentration damages kidney tubule cells via free oxygen radicals and increased lipid peroxidation and this process facilitates both the formation of $\mathrm{CaOx}$ crystals and their attachment to the kidney tubular epithelium $[4,5]$.

Despite the improvements in renal stone treatment, the recurrence rates of $10 \%$ in one year, $35 \%$ in five years, and $50 \%$ in ten years were reported for calcium oxalate stones $[6,7]$. These high recurrence rates have led researchers to explore potential preventive methods for the recurrence of $\mathrm{CaOx}$ stones [6-8].

Quercetin is a flavanol found in various foods, including nuts, wine, seeds, and some fruits and vegetables [8]. In addition to its potent antioxidant, radical scavenging, and anti-inflammatory activities, it also has antibacterial, antiviral, gastroprotective, and immune-modulating activities [8-10].

An increase in oxidative stress was shown in patients with kidney stones [11]. As such, a lower risk of nephrolithiasis was reported in patients with high antioxidant levels than those with low antioxidant levels [12]. It was shown that the Randall plaques, which are thought to be formed due to oxidative stress, have an essential role in $\mathrm{CaOx}$ stone recurrence [13]. Therefore, inhibition of Randall plaque formation and oxidative stress may be beneficial for preventing stone recurrence.

This study investigated the possible protective effect of quercetin in nephrolithiasis and nephrocalcinosis by determining its impact on oxidative stress and inflammation in a rat hyperoxaluria model.

\section{Materials and Methods}

\subsection{Animals}

Male Wistar-Albino rats weighing 250-300 $\mathrm{g}(n=24)$ were used in this experimental study, conducted at the Süleyman Demirel University Experimental Animal Laboratory. Rats were housed in a room maintained at $25 \pm 1{ }^{\circ} \mathrm{C}$ with $55 \%$ relative humidity. They were given food and water ad libitum. The study was conducted after taking approval from Süleyman Demirel University Animal Experiments Ethical Review Committee (approval number: 33/01). All experiments were performed based on the ethical principles reported in European Union Directive 2010/63/EU for animal experiments.

\subsection{Chemicals}

Ethylene glycol (EG) was purchased from Merck Chemicals (Darmstadt, Germany), while quercetin was purchased from Sigma Chemicals (St. Louis, MO, USA).

\subsection{Hyperoxaluria-Induced Nephrolithiasis Model and Quercetin Administration}

The rats were randomly divided into three groups; control $(n=8)$, EG $(n=8)$, and EG + quercetin $(n=8)$ groups. All rats except for the control group were given $1 \%$ EG-water solution as drinking water for five weeks [14]. A $10 \mathrm{mg} / \mathrm{kg} /$ day dose of quercetin-water solution was administered to the rats in the EG + quercetin group by oral gavage. Twentyfour-hour urine samples were collected from the animals on day 0 before administering EG or quercetin and on days 15 and 30. Rats were anesthetized at the end of the five-week experiment period, and blood samples were collected from the inferior caval vein. Then, the rats were sacrificed, and both kidneys were rapidly excised. Right kidneys were embedded in 10\% neutral-buffered formaldehyde. Left kidneys were washed with cold $0.9 \%$ sodium chloride solution and stored at $-80^{\circ} \mathrm{C}$ until homogenization. 


\subsection{Biochemical Analyses}

Analysis of the plasma oxalate levels was performed by the technique previously described by Ladwig et al. [15]. Urinary oxalate level was determined by the enzymatic Trinity Biotech Oxalate kit (Trinity Biotech pic, St. Louis, MO, USA). Catalase (CAT) is an antioxidant enzyme [10,16]. Catalase activity was measured by the Aebi method [16]. Supernatant protein levels were analyzed by bovine serum albumin using the Lowry method as described in the standard protocol [17]. Malondialdehyde (MDA) levels were also analyzed since MDA is considered a biomarker of oxidative stress [9]. Malondialdehyde levels were measured spectrophotometrically as per the method proposed by Ohkawa et al. [18]. Protein detection was performed using the method described by Lowry et al. [17]. The creatinine levels of plasma and urine were measured by colorimetry as per the Jaffe method; plasma urea concentrations were analyzed by kinetic-colorimetric methods and urease and glutamate dehydrogenase reactions. In contrast, urine calcium levels were measured by an autoanalyzer via Schwarzenbach and the o-Cresolphthalein complex method. Timed urine and blood samples were collected for calculating creatinine clearance. Urine volume (V) was expressed in $\mathrm{mL}$, while serum and urine creatinine levels were expressed in $\mathrm{mg} / \mathrm{dl}$. Creatinine clearance was calculated according to the formula:

Creatinine clearance $(\mathrm{mL} / \mathrm{min})=\mathrm{U}(\mathrm{mg} / \mathrm{dL}) \times \mathrm{V}(\mathrm{mL} / \mathrm{min}) / \mathrm{S}(\mathrm{mg} / \mathrm{dL})[\mathrm{V}$ : Urine volume $(\mathrm{mL} / \mathrm{min})$, U: Urine creatinine $(\mathrm{mg} / \mathrm{dL})$, S: Serum creatinine $(\mathrm{mg} / \mathrm{dL})]$

\subsection{Histopathological Analyses}

The right kidneys were embedded into 10\% neutral-buffered formaldehyde (MerckKGaA, Darmstadt, Germany). The tissue processing was initiated after a $24-48 \mathrm{~h}$ fixation period. Kidney tissues were stained with hematoxylin and eosin (H\&E) and examined under a light microscope. Histopathological examinations were performed by $10 \times, 20 \times$, and $40 \times$ magnifications, particularly for assessing vascular congestion in both medulla and cortical glomeruli, the intensity of mononuclear cell infiltration, and sizes and shapes of the tubular lumina.

\subsection{Immunohistochemical Analyses}

Nuclear transcription factor-kB (NF-kB) and p38 mitogen-activated protein kinase (p38-MAPK) are the two main signaling pathways at the protein level in proinflammatory cytokine biosynthesis [19]. In addition, oxalate selectively activates the p38-MAPK signaling pathway [20]. Slides were taken into the incubation container after blockage. The NF-kB/p65 antibody (Santa Cruz, sc-109) was added to the first section, MAPK/p38 antibody (Santa Cruz, sc-7149) to the second section, and a secondary antibody (Goat anti-polyvalent, Thermo) was added to the subsequent sections for control purposes and kept at $+4{ }^{\circ} \mathrm{C}$ overnight. The ABC Staining Kit (Santa Cruz, sc-2018) was used for the rest of the staining protocol. The tissue covered with lamella using Entella was stored and dried for examining with a light microscope. The sections were graded as follows, depending on the intensity of staining in light microscopy, as in the study by Liu HS et al. [19]:

$(-)$ score (negative score): no staining;

$(+)$ score (1 positive score): mild;

$(++)$ score (2 positive scores): moderate;

$(+++)$ score (3 positive scores): complete staining is present.

\subsection{Statistics}

Statistical analysis was performed using Statistical Package for Social Sciences 11.0 (SPSS 11.0) software. Values were given as means \pm standard deviations. The normal distribution of the variables was tested by a single sample Kolmogorov-Smirnov test. A one-way ANOVA was conducted and, if shown to be significant, Duncan's post hoc test was used to evaluate and determine the differences between the groups. The $p$ value was considered significant when it was below $<0.05$. 


\section{Results}

\subsection{Biochemical Results}

Study group data are shown in Table 1. The mean MDA level of the EG group was higher than the control group, while the mean MDA level of the quercetin group was significantly lower than the EG group $(p=0.001)$. There was no statistically significant difference between the groups in terms of CAT activity. In our study, MDA levels were reduced by quercetin, while CAT activity was not affected by quercetin. Urinary oxalate levels were significantly higher in the EG group than the other groups $(p<0.001)$. However, the urinary oxalate levels of the quercetin group were significantly lower than the EG group $(p<0.001)$. These results indicated that quercetin reduced the urinary oxalate levels, which were increased by EG administration. While the plasma urea concentration increased significantly in the EG group compared to in the control group, a statistically significant decrease was observed in the quercetin group compared to the EG group $(p<0.05)$. There was no statistically significant difference between the groups in terms of creatinine clearance and plasma oxalate levels $(p>0.05)$. Although quercetin decreased plasma oxalate level, this was not statistically significant. Urinary calcium concentration was significantly lower in the other groups than the control group $(p<0.05)$. However, there was no statistically significant difference between EG and quercetin groups in terms of mean urinary calcium concentrations. Altogether these findings indicate that EG increased urinary oxalate excretion and plasma urea concentration and decreased urinary calcium concentrations.

Table 1. Statistical data of the study groups and Duncan's multiple range test results.

\begin{tabular}{ccccc}
\hline Biochemical Variables & Control $(\boldsymbol{n}=\mathbf{8})$ & EG $(\boldsymbol{n}=\mathbf{8})$ & EG + Quercetin $(\boldsymbol{n}=\mathbf{8})$ & $\boldsymbol{p}$ Values \\
\hline MDA $(\mathrm{nmol} / \mathrm{mg}$ protein) & $4.53 \pm 0.89^{\mathrm{a}}$ & $7.40 \pm 1.64^{\mathrm{b}}$ & $5.41 \pm 0.82^{\mathrm{a}}$ & 0.0001 \\
\hline $\mathrm{CAT}(\mu \mathrm{mol} / \mathrm{min} / \mathrm{mg})$ & $118.41 \pm 26.02^{\mathrm{a}}$ & $119.48 \pm 16.55^{\mathrm{a}}$ & $131.06 \pm 28.99^{\mathrm{a}}$ & 0.360 \\
\hline $\mathrm{P}_{\text {Urea }}(\mathrm{mg} / \mathrm{dL})$ & $42.37 \pm 3.37^{\mathrm{a}}$ & $86.75 \pm 61.44^{\mathrm{b}}$ & $51.62 \pm 19.97^{\mathrm{a}}$ & 0.040 \\
\hline $\mathrm{U}_{\text {Calcium }}(\mathrm{mg} / \mathrm{dL})$ & $12.90 \pm 3.37^{\mathrm{a}}$ & $8.38 \pm 3.39^{\mathrm{b}}$ & $9.58 \pm 5.59^{\mathrm{b}}$ & 0.046 \\
\hline Creatinine Clearance $(\mathrm{mL} / \mathrm{min})_{\mathrm{P}_{\text {Oxalate }}(\mu \mathrm{mol} / \mathrm{L})}$ & $0.26 \pm 0.09^{\mathrm{a}}$ & $0.50 \pm 0.28^{\mathrm{a}}$ & $0.42 \pm 0.25^{\mathrm{a}}$ & 0.174 \\
\hline $\mathrm{U}_{\text {Oxalate }}(\mu \mathrm{mol} / 24 \mathrm{~h})$ & $32.18 \pm 19.28^{\mathrm{a}}$ & $71.92 \pm 61.83^{\mathrm{a}}$ & $47.48 \pm 20.09^{\mathrm{a}}$ & 0.117 \\
\hline
\end{tabular}

Data shown in different letters such as ${ }^{a, b, c}$ denotes $p<0.05$. EG ethylene glycol, MDA malondialdehyde, CAT catalase, $P_{\text {Urea }}$ plasma urea levels, $\mathrm{U}_{\text {Calcium }}$ urine calcium levels, $\mathrm{P}_{\text {Oxalate }}$ plasma oxalate levels, $\mathrm{U}_{\text {Oxalate }}$ urine oxalate levels.

\subsection{Histopathological Results}

Histopathological examinations of the control group rat kidneys under light microscopy revealed normal findings (Figure 1-Control). Findings, including congestion in glomerular vessels, mononuclear cell infiltration, and narrowing of the tubular lumens, especially in the proximal tubules, were detected in the EG group (Figure 1-EG). Similar histopathological findings were observed in the quercetin group, but they were all milder (Figure 1-EG + quercetin). However, no scoring system was used to evaluate whether this difference was statistically significant.

\subsection{Immunohistochemical Results}

The impact of quercetin on p38 mitogen-activated protein kinase (p38-MAPK) and nuclear factor kappa B (NF-kB) was investigated by immunohistochemical staining of the renal tissues (Figure 2). Comparison of the groups in terms of p38-MAPK elucidated that renal tissues of the EG group rats were stained significantly more intensely than those of the control group rats $(p<0.001)$. On the other hand, p38-MAPK staining was significantly less intense in the quercetin group than in the EG group. The statistical analysis revealed that quercetin reduced p38-MAPK activity significantly compared to the EG group $(p<0.004)$. 


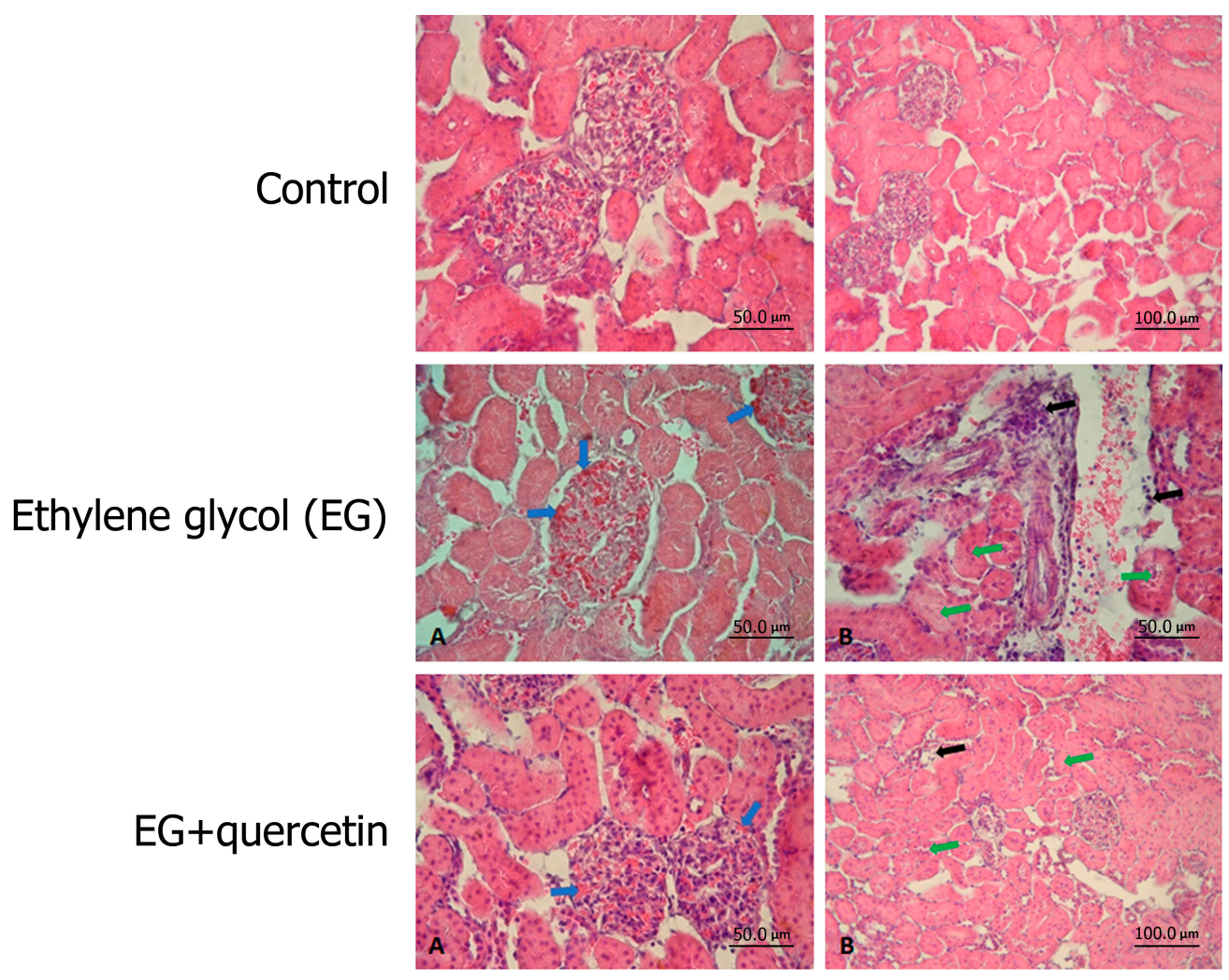

Figure 1. Hematoxylin and eosin (H\&E) stain of kidney tissue and histopathological assessment of all groups. Control: Samples with normal kidney tissue structure. Ethylene glycol (EG): (B) Sample with apparent mononuclear cell infiltration in kidney medulla and cortex layers (black arrow), as well as narrowing of the lumen of the tubules (green arrow). (A) Sample with apparent vascular congestion in both medulla and cortical glomeruli (blue arrow). EG + quercetin: (A) In this tissue sample, decreased vascular congestion in both the medulla and cortical glomeruli are observed. (blue arrow). (B) In this tissue sample, decreased mononuclear cell infiltration in renal medulla and cortex layer (black arrow), and a return to normal structure in the lumen of tubules (green arrow) are observed.

A comparison of the groups concerning NF-kB immunostaining revealed that renal tissues of the rats in the EG group were stained significantly more intensely than those of the rats in the control group $(p<0.001)$. There was no statistically significant difference between the other groups in terms of the intensity of NF-kB staining. Altogether, these findings pointed out that EG induced the p38-MAPK and NF-kB activities in renal tissues. Additionally, quercetin significantly reduced p38-MAPK activity while it had no significant effect on NF-kB activity. The relevant data are displayed in Table 2.

Table 2. Statistical data between groups in terms of p38-MAPK and NF-kB (Mann-Whitney test).

\begin{tabular}{cccc}
\hline $\begin{array}{c}\text { Immunohistochemical } \\
\text { Variables }\end{array}$ & $\begin{array}{c}\text { Comparison of Groups } \\
\text { Control and EG }\end{array}$ & $\begin{array}{c}\text { Comparison of Groups } \\
\text { Control and EG + Quercetin }\end{array}$ & $\begin{array}{c}\text { Comparison of Groups EG } \\
\text { and EG + Quercetin }\end{array}$ \\
\hline p38-MAPK & $p<0.001$ & $p>0.036$ & $p<0.004$ \\
\hline NF-kB & $p<0.001$ & $p>0.227$ & $p>0.054$ \\
\hline
\end{tabular}

EG ethylene glycol, p38-MAPK p38 mitogen-activated protein kinase, NF-kB nuclear factor kappa B. 


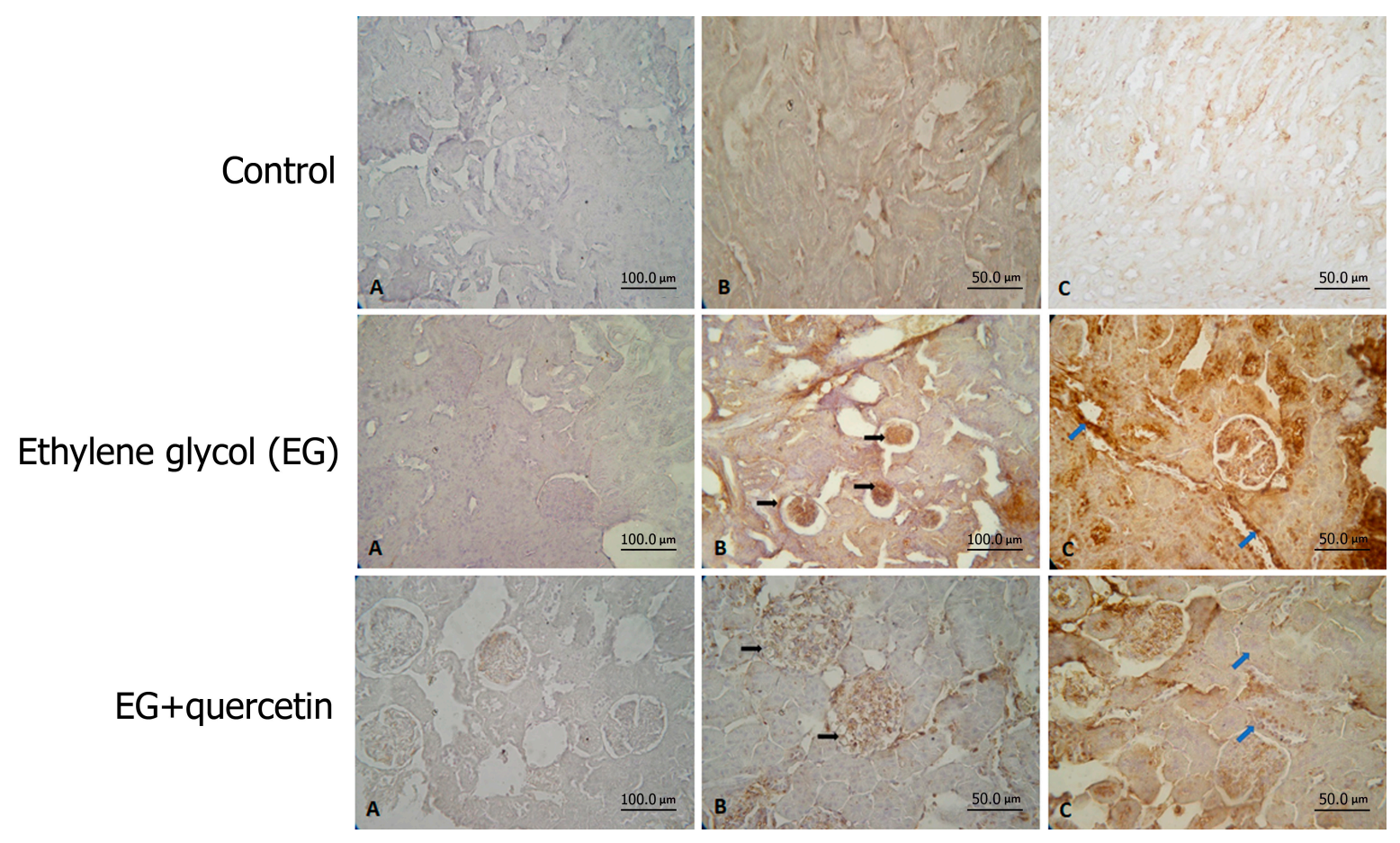

Figure 2. p38-MAPK and NF-kB stain of kidney tissue, and immunohistochemical assessment of all groups. Control: Samples with normal kidney tissue structure. Positive staining of p38-MAPK and NF-kB is not detected in the samples. Staining control (A), p38-MAPK (B) and NF-kB (C). Ethylene glycol (EG): Significant positive staining of p38-MAPK and NF-kB is detected in the samples compared to the control group. Staining control (A), p38-MAPK (B) and NF-kB (C). EG + quercetin: Decreased positive staining of p38-MAPK and NF-kB is detected in the samples compared to the ethylene glycol group. Staining control (A), p38-MAPK (B) and NF-kB (C).

\section{Discussion}

Despite advances in minimally invasive methods for treating nephrolithiasis, high residual stone and recurrence rates still constitute severe problems for the patients and urologists [21]. Therefore, effective medical treatment strategies are needed.

The exact mechanisms of stone formation have not been identified; however, it is known that approximately $80 \%$ of kidney stones contain $\mathrm{CaOx}$ and one of the most common causes of $\mathrm{CaOx}$ stones is hyperoxaluria [1,22]. Oxalate is a by-product of normal metabolism, eliminated from the body under normal conditions [20]. In hyperoxaluria, excess urinary oxalate combines with calcium at physiological $\mathrm{pH}$ and forms $\mathrm{CaOx}$ crystals, accumulating in the kidneys. The $\mathrm{CaOx}$ crystals were shown to damage kidney tubular epithelial cells and lead to renal stone disease $[14,20]$. Therefore, hyperoxaluria rat models were widely used to mimic kidney stone formation in humans. In these studies, EG was used as a hyperoxaluria-inducing agent, as it was the case in our study $[14,20]$.

It was reported that the oxalate concentration in urine increased within two days, hyperoxaluria developed within three days, $\mathrm{CaOx}$ crystalluria developed within two weeks, and $\mathrm{CaOx}$ nephrolithiasis was observed within $4-6$ weeks when $0.75-1 \%$ EG was administered for inducing hyperoxaluria $[14,22]$. At the end of this process, other urinary factors and creatinine clearance remained within normal limits, while urinary $\mathrm{pH}$ and citrate excretion were significantly reduced [14,22]. In our study, we induced hyperoxaluria by administering $1 \%$ EG, which subsequently led to cellular damage in tubular cells.

In hyperoxaluria, accumulation of the $\mathrm{CaOx}$ crystals in renal papilla collector duct lumina and resultant stone-like deposits lead to the obstruction, which paves the way for renal deterioration. As a result of this process, blood levels of nitrogenous waste products, such as uric acid, blood urea nitrogen, and creatinine, may increase [22,23]. In our study, renal dysfunction was demonstrated by a marked increase in serum urea levels 
in the animals treated with EG. However, quercetin treatment significantly reduced serum urea levels.

Quercetin is a molecule with potent antioxidant and anti-inflammatory effects [24]. It is found in vegetables, fruits, tea, and numerous types of food. In addition to being the strong scavenger of reactive oxygen species (ROS), quercetin increases the total plasma antioxidant capacity $[25,26]$. It was reported in some studies that flavonoids reduce oxidative stress in kidney tubular cells, prevent the accumulation of $\mathrm{CaOx}$ crystals, and reduce lipid peroxidation induced by oxalate in cell cultures $[27,28]$.

It is widely accepted that oxidative stress plays a significant role in the formation of kidney stones [12,22]. The $\mathrm{CaOx}$ crystals accumulated in the kidney tissue leading to the synthesis of several macromolecules that initiate inflammatory and fibrogenic processes. Reactive oxygen species are most likely involved in various signaling events during this period [14]. In both animal and kidney epithelial cell culture studies, the free radical formation was shown in response to hyperoxaluria and CaOx crystal formation [20,22]. Since lipids are the most sensitive biomolecules in the cell membrane against free radicals, lipid peroxidation occurs in the cell membranes $[27,28]$. Lipid peroxidation is the primary event of cellular damage since it disrupts the membrane structure and subsequently causes cell damage. The MDA is an indicator of lipid peroxidation; it also indicates that ROS are overproduced [22,29]. Therefore it is used in the evaluation of lipid peroxidation. It is known that the damage caused by $\mathrm{CaOx}$ crystal deposition and the formation of ROS can be prevented or reduced by endogenous antioxidants such as superoxide dismutase (SOD), CAT, and glutathione peroxidase (GSH-Px) $[20,22,29]$. In the present study, MDA levels were found to increase in an experimental animal model of hyperoxaluric nephrolithiasis, which was successfully created by ethylene glycol administration. Our study also showed that quercetin reduced the oxidative stress-enhancing effect of hyperoxaluria, as demonstrated by both biochemical and histopathological parameters.

It is known that ROS activate signal molecules such as protein kinase C (PKC), c-Jun N-terminal kinase (JNK), and p38-MAPK [21]. Activation of these signal molecules leads to the induction of NF-kB and active protein-1 (AP-1) transcription factors. As a result of these events, expression of the proteins such as monocyte chemoattractant protein-1 (MCP-1), osteopontin (OPN), fibronectin, and transforming growth factor beta 1 (TGF- $\beta 1$ ) increase [20]. These proteins facilitate the adhesion of $\mathrm{CaOx}$ crystals and the relevant inflammatory processes [20]. Peerapen et al. reported that p38-MAPK signaling pathways mediated disruption of the tight connections between the epithelial cells [30]. They also showed that the expression of the proteins involved in the p38-MAPK signaling pathway increased during calcium oxalate stone formation. It was also demonstrated that oxalate selectively activated the p38-MAPK signaling pathway, which had an essential role in the nephrotoxicity of oxalate in human kidney epithelial cells [31]. Shiyong Qi et al. proved that $\mathrm{CaOx}$ crystals induced the enhancement of adhesion molecules in proximal tubular epithelial cells, and this process was mediated by the p38-MAPK signaling pathway [31]. Our study showed that oxalate induced p38-MAPK and NF-kB activation. Additionally, we showed that quercetin significantly reduced the activity of p38-MAPK. Based on this information, it can be suggested that quercetin can prevent the recurrence of $\mathrm{CaOx}$ stones.

The study has some limitations. The first is that there was no control group administered quercetin alone. Therefore, the effect of orally administered quercetin on the production and intestinal absorption of oxalate has not been clearly evaluated. Second, the effect of quercetin on ethylene glycol absorption was also not evaluated. Consequently, further research is needed to clarify the mechanism of action of quercetin on hyperoxaluria.

\section{Conclusions}

We conclude that quercetin inhibited the inflammatory and oxidative processes triggered by hyperoxaluria in renal tissues. Since these processes lead to $\mathrm{CaOx}$ stone formation, quercetin can be considered in the preventive medical treatment of recurrent $\mathrm{CaOx}$ stones. Nevertheless, further experimental and clinical research is needed to validate our findings. 
Author Contributions: Conceptualization, S.Y., A.G. and T.O.; methodology, S.Y., O.E., I.A.C., M.C.; software, I.O., M.O.; validation, M.O., M.C. and I.A.C.; formal analysis, I.O., I.A.C., M.O., M.C.; investigation, S.Y.; resources, O.E., A.G.; data curation, S.Y., A.G.; writing-original draft preparation, A.G.; writing-review and editing, A.G., T.O.; visualization, S.Y., O.E.; supervision, T.O.; project administration, T.O.; funding acquisition, S.Y., T.O. All authors have read and agreed to the published version of the manuscript.

Funding: This research was funded by Suleyman Demirel University Scientific Research Project Coordination Unit, grant number 2429-TU-10.

Institutional Review Board Statement: The study was conducted according to the guidelines of the Declaration of Helsinki, and approved by the Institutional Review Board of Suleyman Demirel University Animal Experiments Ethical Review Committee (approval number: 33/01; approval date: 30 November 2010). All experiments were performed based on the ethical principles reported in European Union Directive 2010/63/EU for animal experiments.

Informed Consent Statement: Not applicable.

Data Availability Statement: The data of this study are available from the corresponding author upon reasonable request.

Conflicts of Interest: The authors declare no conflict of interest. The funders had no role in the design of the study; in the collection, analyses, or interpretation of data; in the writing of the manuscript, or in the decision to publish the results.

\section{References}

1. Gambaro, G.; Vezzoli, G.; Casari, G.; Rampoldi, L.; D’Angelo, A.; Borghi, L. Genetics of hypercalciuria and calcium nephrolithiasis: From the rare monogenic to the common polygenic forms. Am. J. Kidney Dis. 2004, 44, 963-986. [CrossRef]

2. Coe, F.L.; Parks, J.H.; Asplin, J.H. The pathogenesis and treatment of kidney stones. N. Engl. J. Med. 1992, 327, 1141-1152. [CrossRef] [PubMed]

3. Khan, S.R.; Pearle, M.S.; Robertson, W.G.; Gambaro, G.; Canales, B.K.; Doizi, S.; Traxer, O.; Tiselius, H.G. Kidney stones. Nat. Rev. Dis. Primers 2016, 2, 16008. [CrossRef]

4. Sun, X.Y.; Xu, M.; Ouyang, J.M. Effect of Crystal Shape and Aggregation of Calcium Oxalate Monohydrate on Cellular Toxicity in Renal Epithelial Cells. ACS Omega 2017, 2, 6039-6052. [CrossRef] [PubMed]

5. Jonassen, J.A.; Kohjimoto, Y.; Scheid, C.R.; Schmidt, M. Oxalate toxicity in renal cells. Urol. Res. 2005, 33, 329-339. [CrossRef] [PubMed]

6. Hess, B.; Ryall, R.L.; Kavanagh, J.P.; Khan, S.R.; Kok, D.J.; Rodgers, A.L.; Tiselius, H.G. Methods for measuring crystallization in urolithiasis research: Why, how and when? Eur. Urol. 2001, 40, 220-230. [CrossRef]

7. Menon, M.; Koul, H. Clinical review 32: Calcium oxalate nephrolithiasis. J. Clin. Endocrinol. Metab. 1992, 74, 703-707. [CrossRef]

8. Anand David, A.V.; Arulmoli, R.; Parasuraman, S. Overviews of Biological Importance of Quercetin: A Bioactive Flavonoid. Pharmacogn. Rev. 2016, 10, 84-89. [PubMed]

9. Abdelhalim, M.A.K.; Moussa, S.A.A.; Qaid, H.A.Y. The protective role of quercetin and arginine on gold nanoparticles induced hepatotoxicity in rats. Int. J. Nanomed. 2018, 13, 2821-2825. [CrossRef] [PubMed]

10. Yarahmadi, A.; Zal, F.; Bolouki, A. Protective effects of quercetin on nicotine induced oxidative stress in 'HepG2 cells'. Toxicol. Mech. Methods 2017, 27, 609-614. [CrossRef]

11. Huang, H.S.; Ma, M.C.; Chen, C.F.; Chen, J. Lipid peroxidation and its correlations with urinary levels of oxalate, citric acid, and osteopontin in patients with renal calcium oxalate stones. Urology 2003, 62, 1123-1128. [CrossRef]

12. Khan, S.R. Reactive oxygen species as the molecular modulators of calcium oxalate kidney stone formation: Evidence from clinical and experimental investigations. J. Urol. 2013, 189, 803-811. [CrossRef]

13. Evan, A.P.; Worcester, E.M.; Coe, F.L.; Williams, J., Jr.; Lingeman, J.E. Mechanisms of human kidney stone formation. Urolithiasis 2015, 43 (Suppl. 1), 19-32. [CrossRef] [PubMed]

14. Khan, S.R. Nephrocalcinosis in animal models with and without stones. Urol. Res. 2010, 38, 429-438. [CrossRef]

15. Ladwig, P.M.; Liedtke, R.R.; Larson, T.S.; Lieske, J.C. Sensitive spectrophotometric assay for plasma oxalate. Clin. Chem. 2005, 51, 2377-2380. [CrossRef] [PubMed]

16. Aebi, H. Catalase. In Method of Enzymatic Analysis, 2nd ed.; Bergmeyer, H.U., Ed.; Academic Press: New York, NY, USA, 1974; pp. 673-684.

17. Lowry, O.H.; Rosebrough, N.J.; Farr, A.L.; Randall, R.J. Protein measurement with the Folin phenol reagent. J. Biol. Chem. 1951, 193, 265-275. [CrossRef]

18. Ohkawa, H.; Ohishi, N.; Yagi, K. Assay for lipid peroxides in animal tissues by thiobarbituric acid reaction. Anal. Biochem. 1979, 95, 351-358. [CrossRef] 
19. Liu, H.S.; Pan, C.E.; Liu, Q.G.; Yang, W.; Liu, X.M. Effect of NF-kappaB and p38 MAPK in activated monocytes/macrophages on pro-inflammatory cytokines of rats with acute pancreatitis. World J. Gastroenterol. 2003, 9, 2513-2518. [CrossRef]

20. Khan, S.R. Hyperoxaluria-induced oxidative stress and antioxidants for renal protection. Urol. Res. 2005, 33, 349-357. [CrossRef]

21. Zhu, W.; Xu, Y.F.; Feng, Y.; Peng, B.; Che, J.P.; Liu, M.; Zheng, J.H. Prophylactic effects of quercetin and hyperoside in a calcium oxalate stone forming rat model. Urolithiasis 2014, 42, 519-526. [CrossRef]

22. Ozturk, H.; Cetinkaya, A.; Firat, T.S.; Tekce, B.K.; Duzcu, S.E.; Ozturk, H. Protective effect of pentoxifylline on oxidative renal cell injury associated with renal crystal formation in a hyperoxaluric rat model. Urolithiasis 2019, 47, 415-424. [CrossRef]

23. Gadge, N.B.; Jalalpure, S.S. Curative treatment with extracts of Bombax ceiba fruit reduces risk of calcium oxalate urolithiasis in rats. Pharm. Biol. 2012, 50, 310-317. [CrossRef] [PubMed]

24. Oboh, G.; Ademosun, A.O.; Ogunsuyi, O.B. Quercetin and Its Role in Chronic Diseases. Adv. Exp. Med. Biol. 2016, 929, 377-387. [PubMed]

25. Arts, M.J.T.J.; Dallinga, J.S.; Voss, H.P.; Haenen, G.R.M.M.; Bast, A. A new approach to assess the total antioxidant capacity using the TEAC assay. Food Chem. 2004, 88, 567-570. [CrossRef]

26. Boots, A.W.; Haenen, G.R.; Bast, A. Health effects of quercetin: From antioxidant to nutraceutical. Eur. J. Pharmacol. 2008, 585, 325-337. [CrossRef] [PubMed]

27. Aggarwal, D.; Gautam, D.; Sharma, M.; Singla, S.K. Bergenin attenuates renal injury by reversing mitochondrial dysfunction in ethylene glycol induced hyperoxaluric rat model. Eur. J. Pharmacol. 2016, 791, 611-621. [CrossRef]

28. Park, H.K.; Jeong, B.C.; Sung, M.K.; Park, M.Y.; Choi, E.Y.; Kim, B.S.; Kim, H.H.; Kim, J.I. Reduction of oxidative stress in cultured renal tubular cells and preventive effects on renal stone formation by the bioflavonoid quercetin. J. Urol. 2008, 179, 1620-1626. [CrossRef] [PubMed]

29. Yang, X.; Ding, H.; Qin, Z.; Zhang, C.; Qi, S.; Zhang, H.; Yang, T.; He, Z.; Yang, K.; Du, E.; et al. Metformin Prevents Renal Stone Formation through an Antioxidant Mechanism In Vitro and In Vivo. Oxidative Med. Cell Longev. 2016, 2016, 4156075. [CrossRef] [PubMed]

30. Peerapen, P.; Thongboonkerd, V. p38 MAPK mediates calcium oxalate crystal-induced tight junction disruption in distal renal tubular epithelial cells. Sci. Rep. 2013, 3, 1041. [CrossRef]

31. Qi, S.; Wang, Q.; Xie, B.; Chen, Y.; Zhang, Z.; Xu, Y. P38 MAPK signaling pathway mediates COM crystal-induced crystal adhesion change in rat renal tubular epithelial cells. Urolithiasis 2020, 48, 9-18. [CrossRef] 